\title{
Intra-erythrocyte cation concentrations in relation to the C1797T $\beta$-adducin polymorphism in a general population
}

\author{
T Richart ${ }^{1}$, L Thijs ${ }^{1}$, T Kuznetsova ${ }^{1}$, V Tikhonoff ${ }^{1,2}$, L Zagato ${ }^{3}$, P Lijnen ${ }^{1}$, R Fagard ${ }^{1}$, J Wang ${ }^{4}$, \\ G Bianchi ${ }^{3}$ and JA Staessen ${ }^{1}$ \\ ${ }^{1}$ Division of Hypertension and Cardiovascular Rehabilitation, Department of Cardiovascular Diseases, \\ Studies Coordinating Centre, University of Leuven, Leuven, Belgium; ${ }^{2}$ Department of Clinical and \\ Experimental Medicine, University of Padua, Padua, Italy; ${ }^{3}$ Division of Nephrology, Dialysis and \\ Hypertension, University Vita Salute San Raffaele, Milan, Italy and ${ }^{4}$ Centre for Epidemiological Studies and \\ Clinical Trials, Ruijin Hospital, Shanghai Institute of Hypertension, Shanghai, China
}

Genetic variability in the ADD1 (Gly460Trp) and ADD2 (C1797T) subunits of the cytoskeleton protein adducin plays a role in the pathogenesis of hypertension, possibly via changes in intracellular cation concentrations. ADD2 1797CC homozygous men have decreased erythrocyte count and hematocrit. We investigated possible association between intra-erythrocyte cations and the adducin polymorphisms. In 259 subjects (mean age 47.7 years), we measured intra-erythrocyte $\mathrm{Na}^{+}$ [iNa], $\mathbf{K}^{+}[\mathrm{iK}]$ and $\mathbf{M g}^{2+}$ [iMg], serum cations and adducin genotypes. Genotype frequencies (ADD1: GlyGly 61.5\%, Trp 38.5\%; ADD2: CC $80.4 \%$, T 19.6\%) complied with Hardy-Weinberg proportions. In men, ADD2 CC homozygotes $(n=100)$ compared to T-carriers $(n=23)$ had slightly lower iK $(85.8$ versus $87.5 \mathrm{mmol} / \mathrm{l}$ cells; $\boldsymbol{P}=$ 0.107 ), higher iMg (1.92 versus $1.80 \mathrm{mmol} / \mathrm{l}$ cells; $P=$ $0.012)$, but similar iNa $(6.86$ versus $6.88 \mathrm{mmol} / \mathrm{l}$ cells;
$P=0.93)$. In men, iK, iMg and iNa did not differ according to ADD1 genotypes. In men, iK $\left(R^{2}=0.128\right)$ increased with age and serum $\mathrm{Na}^{+}$, but decreased with serum total calcium and the daily intake of alcohol. iMg $\left(R^{2}=0.087\right)$ decreased with age, but increased with serum total calcium. After adjustment for these covariates $(P \leqslant 0.04$ for all), findings in men for iK (CC versus T: 85.8 versus $87.3 \mathrm{mmol} / \mathrm{l} ; P=0.14)$ and $\mathrm{iMg}(1.91$ versus $1.82 \mathrm{mmol} / \mathrm{l}$; $P=0.03)$ remained consistent. In 136 women, none of the phenotype-genotype relations reached significance. Changes in intra-erythrocyte cations in ADD2 1797CC homozygous men might lead to osmotic fragility of erythrocytes, but to what extent they reflect systemic changes or are possibly involved in blood pressure regulation remains unknown.

Journal of Human Hypertension (2007) 21, 387-392.

doi:10.1038/sj.jhh.1002154; published online 15 February 2007

Keywords: adducin; erythrocytes; polymorphism; genetics; osmotic

\section{Introduction}

The membrane-skeleton protein adducin stimulates the assembly of the spectrin-actin network, which determines the structural integrity of the cell membrane. Adducin is composed of either $\alpha$ - and $\beta$ - or $\alpha$ - and $\gamma$-subunits, which are encoded by different genes. In erythrocytes, $\alpha$ - and $\beta$-adducin are abundantly present, whereas most other tissues predominantly express $\alpha-\gamma$-heterodimers. $\beta$-Adducin

Correspondence: Dr JA Staessen, Studies Coordinating Centre, Laboratory of Hypertension, Hypertension and Cardiovascular Rehabilitation Unit, Department of Cardiovascular Diseases, Campus Gasthuisberg, Herestraat 49, box 702, Leuven, B-3000 Belgium.

E-mail: jan.staessen@med.kuleuven.be

Received 21 August 2006; revised 27 November 2006; accepted 10 December 2006; published online 15 February 2007 knockout mice show a phenotype characterised by mild anemia and compensated hemolysis. ${ }^{1,2}$ In humans, a common polymorphism (C1797T) occurs in exon 15 of the $\beta$-adducin gene. We have demonstrated previously in cross-sectional and prospective studies that genetic variability in the subunits of the cytoskeleton protein adducin plays a role in the pathogenesis of hypertension, possibly via alteration of the intracellular cation concentrations. ${ }^{3,4}$ In addition, we have recently noticed that in men consuming alcohol, $\beta$-adducin CC homozygosity was associated with lower erythrocyte count, haemoglobin level and haematocrit. ${ }^{5}$ The osmotic stability of erythrocytes decreases with lower intracellular potassium concentration. ${ }^{6}$ We therefore measured the intra-erythrocyte concentration of cations in a sub-sample of our previous study population $^{5}$ to test possible association with the $\alpha$ - and $\beta$-adducin polymorphisms. 


\section{Methods}

\section{Study population}

The Ethics Committee of the University of Leuven approved the protocol of the Flemish study on Environment, Genes and Health Outcomes (FLEMENGHO). All subjects gave informed consent. From August 1985 to November 1990, we recruited a random sample of the households living in a geographically defined area of Northern Belgium. ${ }^{7}$ We stratified the sample by sex and age (20-39, $40-59$ and $\geqslant 60$ years) to recruit equal numbers of participants in each of the six strata. From June 1996 to December 2000, we enrolled nuclear families, using the former participants (1985-1990) as index persons. The participation rate among the 2310 subjects contacted was $66.1 \%$. Our previous study ${ }^{5}$ included 1870 subjects with haematological phenotypes and the C1797T $\beta$-adducin genotype. Of these, 277 subjects were randomly selected and underwent additional measurements of their intra-erythrocyte cation concentrations and the concentration of serum ionised calcium. We excluded 18 subjects, because of missing values.

Trained nurses measured each participant's blood pressure (BP) five times consecutively by conventional sphygmomanometry after the subjects had rested for at least $5 \mathrm{~min}$ in the sitting position. These five readings were averaged for analysis. Hypertension was defined as a $\mathrm{BP}$ of at least $140 \mathrm{~mm} \mathrm{Hg}$ systolic or $90 \mathrm{~mm} \mathrm{Hg}$ diastolic, or as use of antihypertensive drugs. Body mass index (BMI) was body weight in kilograms divided by height in metres squared. We used a standardized and validated $^{8}$ questionnaire to collect information on medical history, smoking habits, intake of alcohol, use of medications and the menstrual cycle of women. From the type and number of alcoholic beverages used each day, we calculated alcohol consumption in grams per day.

\section{Measurement of phenotypes}

Venous blood samples were collected into ethylenediamine-tetraacetic acid-containing tubes. Erythrocyte count, haemoglobin, and haematocrit were measured in whole-blood specimens with a SYSMEX HST 403XE model automated cell counter (Systmex Corporation, Chuku, Kobe, Japan). Serum ionised calcium and $\mathrm{pH}$ were determined using an ICA2 ionised calcium analyser (Radiometer, Copenhagen, Denmark).

Erythrocytes $(1.5 \mathrm{ml})$ were washed three times with ice-cold $140 \mathrm{~mm}$ choline chloride. After centrifugation at 5500 r.p.m. at $4^{\circ} \mathrm{C}$ for $3 \mathrm{~min}$, the supernatant and the top layer of the cells were discarded by aspiration. The cells were lysed with doubledistilled water and the $\mathrm{Na}^{+}, \mathrm{K}^{+}$and $\mathrm{Mg}^{2+}$ concentrations were measured by atomic absorption spectrometry. The intra-assay ( \pm s.e.) variation determined in 10 blood samples was $1.63 \pm 0.31 \%$ for
$\mathrm{iNa}^{+}$and $2.12 \pm 0.12 \%$ for $\mathrm{iK}^{+}$. The inter-assay variation determined in five blood samples was $2.37 \pm 1.03 \%$ for $\mathrm{iNa}^{+}$and $3.22 \pm 1.18 \%$ for $\mathrm{iK}^{+}$.

\section{Determination of genotypes}

Genomic DNA was extracted from peripheral blood. Allelic discrimination of the ADD1 460 glycine (Gly)/460 tryptophan (Trp) and the ADD2 C1797 T polymorphism was carried out using the $5^{\prime}$-nuclease assay $^{9}$ on an ABI Prism 7700 apparatus (Perkin Elmer, Foster City, CA, USA). The forward and reverse primers and the 460Gly and 460Trp probes employed in the TAQMan2 assay were 5'-CGTCCAC ACCTTAGTCTTCGACTT- $3^{\prime}$ 5'-GGAGAAGACAAGA TGGCTGAACTC-3' ${ }^{\prime}, 5^{\prime}$-FAM-TTCCATTCTGCCCTTC CTCGGATAMRA- $3^{\prime}$ and $5^{\prime}$-TET-TTCCATTCTGCCA TTCCTCGGAA-TAMRA-3,' respectively (where FAM, TAMRA and TET are dyes used with the TAQMan system). For the ADD2 C1797T polymorphism, the forward and reverse primers and the 1797C and $1797 \mathrm{~T}$ probes employed in the TAQMan2 assay were 5'-AGG AACGAGAGCCAGGCTCT- $3^{\prime} 5^{\prime}$-TTCATCAAAACAC ACACCTACCAAT-3', $5^{\prime}$-VIC2-TTCTTCAGCGTTGC CCTCCACATTAMRA2- ${ }^{\prime}$ and $5^{\prime}$-FAM2-TCTTCAGT GTTGCCCTCCACATCTG-TAMRA2-3' (where VIC2, TAMRA2 and FAM2 are dyes used with the TAQMan system). Per $25 \mu \mathrm{l}$, the polymerase chain reaction (PCR) fluid contained $50 \mathrm{ng}$ of DNA, $200 \mathrm{nmol}$ of primers, $50 \mathrm{nmol}$ of FAM probe and $100 \mathrm{nmol}$ of VIC probe. The amplification conditions were $50^{\circ} \mathrm{C}$ for $2 \mathrm{~min}$ and $95^{\circ} \mathrm{C}$ for $10 \mathrm{~min}$, followed by 40 cycles at $95^{\circ} \mathrm{C}$ for $15 \mathrm{~s}$ and $62^{\circ} \mathrm{C}$ for $1 \mathrm{~min}$. The genotyping procedure was established after we had confirmed the polymorphism (C1797T, starting from ATG; dbSNP number rs4984; URL: http://www.ncbi.nlm.nih.gov/SNP) by sequencing 17 individuals using the ABI Prism Big Dye Terminator cycle sequencing ready reaction kit (Applied Biosystems, Foster City, CA, USA). We tested the frequency of the polymorphism in a random population of 250 blood donors from North Italy, and found that the minor allele had a frequency of $15 \%$. For quality control, $10 \%$ of the DNA samples in our study were genotyped in duplicate in a blinded fashion. Duplicate genotypes were confirmatory in all samples.

\section{Statistical analysis}

For database management and statistical analysis, we used SAS software, version 9.1.3 and JMP, version 6 (SAS Institute, Cary, NC, USA). Measurements with a skewed distribution were normalised by logarithmic transformation. Comparisons of means and proportions were performed using Student's $t$-test and Fisher's exact test, respectively. We computed Pearson's correlation coefficients between the cation concentrations in erythrocytes and serum and compared these correlation coefficients between women and men using Fisher's $z$-transformation. 
To examine the relationship of the intra-erythrocyte cation concentrations with serum and urinary cations, anthropometric characteristics, and various environmental and lifestyle factors, we used stepwise linear regression analysis with the $P$-value for covariates to enter and stay in the model set at 0.15 . We considered as possible explanatory variables: age, BMI, the serum concentrations of sodium, potassium, magnesium and ionised and total calcium, the 24-hour urinary excretion of sodium, potassium, magnesium and calcium and their excretion ratios, current smoking $(0,1)$ and the quantity of alcohol consumed per day. Because of our previously reported sex-specific findings on the association between hematological phenotypes and genetic polymorphisms, we analysed women and men separately. ${ }^{5,10}$ We performed retrospective power calculations, using the PROC POWER procedure.

\section{Results}

\section{Anthropometric characteristics and cation} measurements

The 259 participants included 136 women (52.3\%) and 32 hypertensive patients $(12.3 \%)$ of whom only one was taking antihypertensive drugs. Age ranged from 20 to 76 years. Table 1 lists the characteristics of the study population by gender. Systolic and diastolic BP, blood haemoglobin concentration, haematocrit and erythrocyte count were lower in women. iNa was higher in men than women, whereas the

Table 1 Characteristic of the study participants

\begin{tabular}{|c|c|c|c|}
\hline Characteristics & $\begin{array}{l}\text { Women } \\
(\mathrm{n}=136)\end{array}$ & $\begin{array}{c}\text { Men } \\
(\mathrm{n}=123)\end{array}$ & $\mathrm{P}$-value \\
\hline Age (years) & $46.8 \pm 13.3$ & $48.7 \pm 13.4$ & 0.25 \\
\hline BMI $\left(\mathrm{kg} / \mathrm{m}^{2}\right)^{\mathrm{a}}$ & $25.2 \pm 3.9$ & $25.9 \pm 3.3$ & 0.11 \\
\hline SBP $(\mathrm{mm} \mathrm{Hg})^{\mathrm{b}}$ & $119.7 \pm 14.5$ & $126.0 \pm 18.5$ & 0.0042 \\
\hline DBP $(\mathrm{mm} \mathrm{Hg})^{\mathrm{b}}$ & $71.4 \pm 8.5$ & $74.5 \pm 8.7$ & 0.0034 \\
\hline Smokers $(n \%)$ & $39(\overline{28.7)}$ & $38(\overline{30.7)}$ & 0.73 \\
\hline $\begin{array}{l}\text { Alcohol intake } \geqslant 5 \mathrm{~g} / \\
\text { day }(n \%)\end{array}$ & $12(8.8)$ & $37(29.8)$ & $<0.0001$ \\
\hline $\begin{array}{l}\text { Contraceptive pill } \\
\text { use }(n \%)\end{array}$ & $15(11)$ & & \\
\hline $\begin{array}{l}\text { Postmenopausal } \\
\text { status }^{\mathrm{c}}(n \%)\end{array}$ & $52(38)$ & & \\
\hline $\begin{array}{l}\text { Haemoglobin } \\
(\mathrm{mmol} / \mathrm{l})\end{array}$ & $8.28 \pm 0.71$ & $9.37 \pm 1.00$ & $<0.0001$ \\
\hline Haematocrit (\%) & $38.3 \pm 2.9$ & $42.7 \pm 2.7$ & $<0.0001$ \\
\hline $\begin{array}{l}\text { Serum erythrocyte } \\
\text { count }\left(10^{12} \text { cells } / \mathrm{l}\right)\end{array}$ & $4.30 \pm 0.38$ & $4.85 \pm 0.34$ & $<0.0001$ \\
\hline
\end{tabular}

Abbreviations: BMI, body mass index, DBP, diastolic blood pressure; SBP, systolic blood pressure.

Plus-minus values are mean \pm s.d.

$P$-values are for the differences between women and men.

${ }^{a}$ Body mass index is weight in kilograms divided by the square of height in metres.

'Only one participant was on anti-hypertensive drug treatment.

${ }^{\mathrm{c}}$ None of the postmenopausal women was on hormonal replacement therapy. opposite was true for iK (Table 2). As expected, the serum concentrations of sodium, potassium and magnesium and the 24-hour urinary excretion of sodium, potassium and calcium were lower in women than men (Table 2).

Smoking was equally prevalent among women and men. The median number of cigarettes smoked per day was 15 (interquartile range (IQR) 10-25). Compared to women, more men reported alcohol intake of at least $5 \mathrm{~g}$ daily (Table 1). Among regular drinkers, the median daily alcohol consumption was $20 \mathrm{~g}$ (IQR 10-23.2) in women and 20 (IQR 10-33.5) in men. Of the premenopausal women, $15(17.9 \%)$ took oral contraceptives. None of the 52 postmenopausal women was on hormone replacement therapy.

In men, we found positive and significant correlations between iMg and serum total calcium $(r=0.22$, $P=0.013)$ and between iK and serum $\mathrm{Mg}^{2+}(r=0.27$, $P=0.029$; Figure 1). In women, the corresponding correlation coefficients were $-0.08(P=0.32)$ and $0.09(P=0.32)$, respectively. The $P$-values for the sex differences in the strength of these associations were 0.14 and 0.013 , respectively.

\section{Phenotype-genotype associations}

The frequencies of the $\alpha$-adducin (ADD1) genotypes (GlyGly 61.5\%, Trp 38.5\%) and the $\beta$-adducin (ADD2) genotypes (CC 80.4\%, T 19.6\%) did not deviate from Hardy-Weinberg equilibrium $(P>0.15)$. Sex distribution, anthropometric characteristics and BP did not differ according to the $\alpha$ - and $\beta$-adducin genotypes.

Table 2 Intra-erythrocyte, serum and urinary cation concentrations

\begin{tabular}{lccc}
\hline Characteristics $^{a}$ & $\begin{array}{c}\text { Women } \\
(\mathrm{n}=136)\end{array}$ & $\begin{array}{c}\text { Men } \\
(\mathrm{n}=123)\end{array}$ & P-value $^{\dagger}$ \\
\hline Intra-erythrocyte & & & \\
$\quad$ Sodium (mmol/l cells) & $6.42 \pm 1.01$ & $6.86 \pm 1.03$ & 0.0005 \\
Potassium (mmol/l & $87.60 \pm 4.32$ & $86.12 \pm 4.58$ & 0.0078 \\
cells) & & & \\
Magnesium (mmol/l & $1.86 \pm 0.20$ & $1.90 \pm 0.22$ & 0.15 \\
cells) & & & \\
& & & \\
Serum & & & \\
Sodium (mmol/l) & $139.9 \pm 1.7$ & $141.0 \pm 1.8$ & $<0.0001$ \\
Potassium (mmol/l) & $4.02 \pm 0.33$ & $4.12 \pm 0.31$ & 0.0209 \\
Magnesium (mmol/l) & $0.80 \pm 0.07$ & $0.83 \pm 0.07$ & 0.0009 \\
Total calcium (mmol/l) & $2.35 \pm 0.09$ & $2.37 \pm 0.10$ & 0.10 \\
Ionised calcium at pH & $1.27 \pm 0.52$ & $1.27 \pm 0.54$ & 0.98 \\
7.4 (mmol/l) & & & \\
& & & \\
Urine & & & \\
Sodium (mmol/24h) & $141 \pm 54$ & $175 \pm 72$ & $<0.0001$ \\
Potassium (mmol/24h) & $67 \pm 22$ & $78 \pm 29$ & 0.0008 \\
Calcium (mmol/24 h) & $4.29 \pm 2.45$ & $5.10 \pm 2.51$ & 0.0087 \\
Magnesium (mmol/ & $4.76 \pm 4.83$ & $5.24 \pm 4.42$ & 0.40 \\
24h) & & & \\
Na/K & $2.31 \pm 1.89$ & $2.35 \pm 0.82$ & 0.81 \\
& & & \\
\hline
\end{tabular}

${ }^{\dagger} P$-values are for the differences between women and men. ${ }^{\text {ap}}$ Plus-minus values are mean + s.d. 

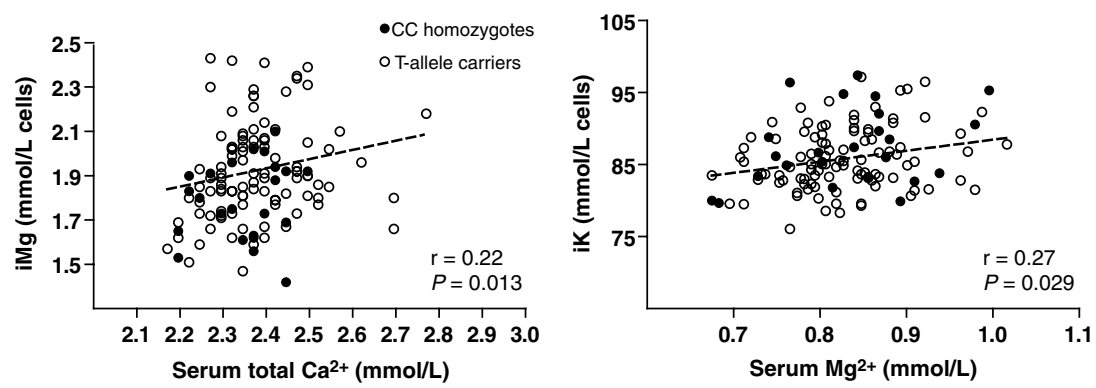

Figure 1 Correlations between cations in erythrocytes and serum in 123 men. Open symbols denote $\beta$-adducin (ADD2) 1797CC homozygotes and closed symbols $\mathrm{T}$ allele carriers.
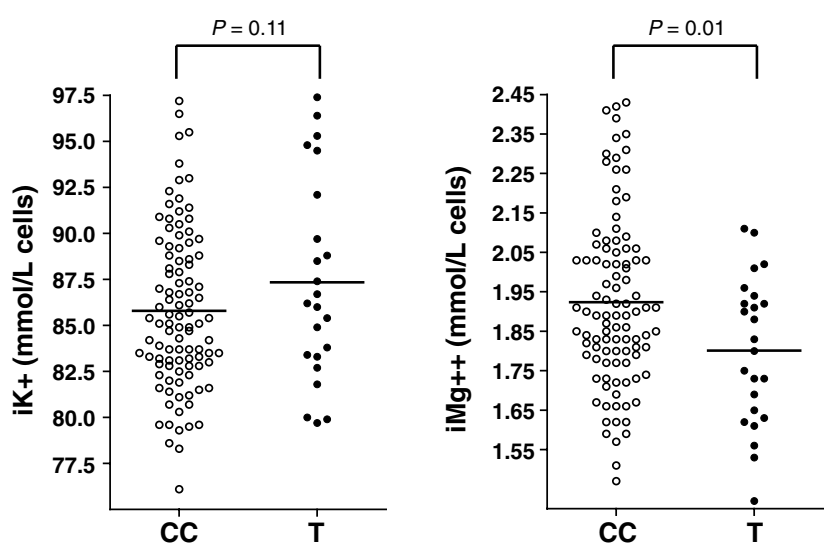

Figure 2 Intra-erythrocyte cation concentrations in 123 men by $\beta$-adducin (ADD2) genotype. Horizontal lines in the scatterplot represent means.

In men, BAD $C C$ homozygotes $(n=100)$ compared to T-carriers $(n=23)$ had slightly lower iK $(85.8$ versus $87.5 \mathrm{mmol} / \mathrm{l}$ cells, $P=0.107)$, higher $\mathrm{iMg}$ (1.92 versus $1.80 \mathrm{mmol} / \mathrm{l}, P=0.012$ ), but similar iNa (6.86 versus $6.88, P=0.93$; Figure 2). In men $\mathrm{iK}$, iMg and iNa did not differ according to the $\alpha$-adducin genotypes or the interaction between the $\alpha$ - and $\beta$-adducin polymorphisms. In 136 women, none of the phenotype-genotype relations reached significance (Table 3, $P>0.49$ ). A sensitivity analysis, from which we excluded hypertensive patients, produced results similar to those reported above, in both men and women. Retrospective power calculations suggested that 120 subjects provided approximately 70 and $60 \%$ power to demonstrate significant $(P<0.05)$ differences on one- and two-sided tests, respectively.

In stepwise regression analysis involving men, iK $\left(R^{2}=0.128\right)$ increased with age $(P=0.029)$ and serum sodium $(P=0.0667)$, but decreased with serum total calcium $(P=0.0456)$ and the amount of alcohol consumed per day $(P=0.0163)$. iMg $\left(R^{2}=\right.$ 0.087) decreased with age $(P=0.0272)$, but increased with serum total calcium $(P=0.0217)$. After adjustment for these covariates, findings in men for iK (CC versus T, 85.8 versus $87.3 \mathrm{mmol} / \mathrm{l}$, $P=0.14)$ and iMg (1.91 versus $1.82 \mathrm{mmol} / \mathrm{l}$, $P=0.03$ ) remained consistent.

\section{Discussion}

The key finding of our study was that in men intraerythrocyte magnesium was on average $0.12 \mathrm{mmol} / \mathrm{l}$ cells lower in $\beta$-adducin 1797T-allele carriers compared to CC homozygotes, with an opposite trend in the intra-erythrocyte potassium concentration. In women, these associations with the ADD2 C1797T polymorphism did not reach statistical significance. In both sexes, none of the phenotype-genotype relations with the $\alpha$-adducin Gly460Trp polymorphism reached significance. In men, there was also no interaction between the ADD1 and ADD2 genotypes in relation to the intra-erythrocyte cation concentrations.

Investigations in rats, ${ }^{11}$ interventions in nevertreated hypertensive patients and epidemiological studies ${ }^{12-14}$ have shown that the Trp point mutation in the $\alpha$-adducin subunit is associated with a phenotype characterised by higher activity of the sodium pump, hence increased tubular sodium reabsorption in the kidney and ultimately hypertension. Alterations in the erythrocyte membrane mirror those in renal tubular cells. Glorioso and co-workers ${ }^{15}$ investigated erythrocytes from 268 never-treated North Sardinian patients with essential hypertension (34.7\% women). They noticed that at $V_{\max }$, the $\mathrm{Na}, \mathrm{K}$-pump, the $\mathrm{Na}, \mathrm{K}, \mathrm{Cl}$-cotransport and the $\mathrm{Li}$, Na-countertransport were faster in $\alpha$-adducin $\operatorname{Tr} p$ allele carriers than GlyGly homozygotes. ${ }^{15}$ The current study included only $12.3 \%$ hypertensive patients and had a sample size, which was insufficient to confirm the well-known associations of BP with the $\alpha$-adducin Gly460Trp polymorphism.

We have demonstrated previously that in men consuming alcohol $\beta$-adducin 1797CC homozygosity was associated with lower erythrocyte count, haemoglobin level and haematocrit. ${ }^{5}$ We hypothesised that male $C C$ homozygotes compared with $T$ allele carriers might have a more fragile erythrocyte membrane and that alcohol intake might unveil this innate greater fragility of erythrocytes. ${ }^{5}$ In other words, the $\beta$-adducin $C C$ genotype might invigorate the structural and functional haematological disturbances associated with excessive alcohol intake. Higher intra-erythrocyte potassium concentration increases the hydration and osmotic stability of 
Table 3 Intra-erythrocyte electrolyte concentrations by genotype (unadjusted)

\begin{tabular}{|c|c|c|c|c|c|c|}
\hline \multirow[b]{2}{*}{ Characteristic $^{\mathrm{a}}$} & \multicolumn{3}{|c|}{$\alpha$-Adducin allele } & \multicolumn{3}{|c|}{$\beta$-Adducin allele } \\
\hline & GlyGly & $\operatorname{Trp}$ & P-value ${ }^{\dagger}$ & CC & $\mathrm{T}$ & P-value \\
\hline \multicolumn{7}{|l|}{ Women } \\
\hline Sodium (mmol/l cells) & $6.45 \pm 0.11$ & $6.37 \pm 0.13$ & 0.66 & $6.40 \pm 1.04$ & $6.49 \pm 0.86$ & 0.91 \\
\hline Potassium (mmol/l cells) & $87.60+0.49$ & $87.59+0.57$ & 0.99 & $87.53+4.50$ & $87.88+3.59$ & 0.93 \\
\hline Magnesium (mmol/l cells) & $1.87 \pm 0.02$ & $1.85 \pm 0.21$ & 0.49 & $1.86 \pm 0.20$ & $1.88 \pm 0.22$ & 0.73 \\
\hline \multicolumn{7}{|l|}{ Men } \\
\hline Sodium (mmol/l cells) & $6.82 \pm 1.01$ & $6.95 \pm 1.07$ & 0.49 & $6.86 \pm 1.04$ & $6.88 \pm 1.00$ & 0.93 \\
\hline Potassium (mmol/l cells) & $85.94+0.51$ & $86.45+0.70$ & 0.56 & $85.80+4.33$ & $87.47+5.41$ & 0.11 \\
\hline Magnesium (mmol/l cells) & $1.90 \pm 0.22$ & $1.90 \pm 0.22$ & 0.85 & $1.92 \pm 0.22$ & $1.80 \pm 0.19$ & 0.01 \\
\hline
\end{tabular}

Abbreviations: Gly, glycine; Trp, tryptophan.

${ }^{\dagger} P$-values are for the significance of differences between genotypes.

aPlus-minus values are mean \pm s.d.

circulating erythrocytes. ${ }^{6}$ We therefore investigated in a subsample of our previous study ${ }^{5}$ possible association between the intra-erythrocyte cation concentrations and the $\beta$-adducin $C 1797 T$ polymorphism. In the current study, male $\beta$-adducin $C C$ homozygotes compared with $T$ allele carriers had a slightly, albeit not significantly lower intra-erythrocyte potassium concentration. These findings are in line with the above hypothesis. ${ }^{5}$

The intra-erythrocyte potassium concentration is regulated via the $\mathrm{K}, \mathrm{Cl}$-cotransport and the $\mathrm{Ca}^{2+}$ activated K-channel, also known as the Gardoschannel. Opening of the channel increases $\mathrm{K}^{+}$efflux through the membrane by three orders of magnitude. ${ }^{16,17}$ Magnesium inhibits the opening of the Gardos channel. Intra-erythrocyte magnesium represents only $0.5 \%$ of the total body content of magnesium. Intra-erythrocyte magnesium and potassium are tightly regulated. ${ }^{18}$ This may explain why, in the current study, we did not find any association between the intra-erythrocyte concentrations of magnesium and potassium. However, the positive correlation between the intra-erythrocyte potassium concentration and serum magnesium is consistent with the notion that magnesium inhibits the Gardos channel ${ }^{19}$ and might increase the intra-erythrocyte potassium concentration. Another potential mechanism affecting cytosolic magnesium is the energy-requiring extrusion, which might be coupled to the movement of other cations. To what extent such ion exchange might underlie the positive correlation between intra-erythrocyte magnesium and serum total calcium remains to be elucidated. Irrespective of the mechanism involved, the difference among men in the intra-erythrocyte magnesium concentration between $C C$ homozygotes and $T$-allele carriers is unlikely to contribute to the hypothesised higher innate fragility of erythrocytes of CC homozygotes.

Several factors might explain the absence of any phenotype-genotype association in women in our previous ${ }^{5}$ as well as in our current study. Haematological phenotypes such as erythrocyte count, haemoglobin level and haematocrit are influenced by menstrual blood loss and by the use of oral contraceptives or hormone replacement therapy. Fluctuations in female sex hormones owing to menopausal status or menstrual cycle may mask haematological phenotypes associated with genetic mutation of the $\beta$-adducin gene.

The present study has to be interpreted within the context of its limitations. We investigated a $13.9 \%$ subsample of our previous study population. ${ }^{5}$ Our study lacked the statistical power to demonstrate the effects of the $\alpha$-adducin Trp allele on BP and the intra-erythrocyte sodium concentration and the effects of alcohol intake per se on erythrocyte count, haemoglobin concentration and haematocrit. ${ }^{5}$ Although the $P$-value for the genotypic difference in intra-erythrocyte magnesium associated with the $\beta$-adducin polymorphism was 0.01 , we cannot exclude with certainty a type 1 error. Our present findings are therefore only hypothesis-generating and are currently being tested in a larger group of never-treated hypertensive patients.

What is known about the topic

- Genetic variability in the ADD1 (Gly460Trp) and ADD2 $(\mathrm{C} 1797 \mathrm{~T})$ subunits of the cytoskeleton protein adducin plays a role in the pathogenesis of hypertension, possibly via changes in intracellular cation concentrations. ${ }^{1,3-5,13}$

- ADD2 1797CC homozygous men have decreased erythrocyte count and haematocrit. ${ }^{5}$

- Intra-erythrocyte cation concentrations affect the osmotic stability of red blood cell membrane. ${ }^{6,16,17}$

What this study adds

- ADD2 1797CC homozygous men exhibit slightly lower concentrations of intra-erythrocyte potassium, higher magnesium but similar sodium compared with T-allele carriers.

- In 136 women, none of the phenotype-genotype relations reached significance.

- Changes in intra-erythrocyte cations in ADD2 1797CC homozygous men might lead to osmotic fragility of erythrocytes, but to what extent they reflect systemic changes or are possibly involved in blood pressure regulation remains unknown. 


\section{Acknowledgements}

The Flemish Study on Environment, Genes and Health Outcomes (FLEMENGHO) is part of the European Project on Genes in Hypertension (EPOGH), which is endorsed by the European Council for Cardiovascular Research and the European Society of Hypertension. FLEMENGHO would not have been possible without the voluntary collaboration of participants and their general practitioners. The municipality Hechtel-Eksel (Belgium) gave logistic support. Research included in the present study was partially funded by the European Union (Grants IC15-CT98-0329-EPOGH and QLGICT-2000-01137-EURNETGEN), the Fonds voor Wetenschappelijk Onderzoek Vlaanderen, Ministry of the Flemish Community, Brussels, Belgium (Grants G.0424.03 and G.0575.06), the Katholieke Universiteit Leuven, Leuven, Belgium (Grants OT/99/28, OT/00/25 and OT/05/49). We gratefully acknowledge the technical assistance of Tamara Coenen, Sandra Covens, Marie-Jeanne Jehoul, Lieve Lommelen, Yvette Piccart, Hanne Truyens, Katrien Staessen and Renilde Wolfs (Studies Coordinating Centre, Leuven, Belgium).

\section{References}

1 Muro AF, Marro ML, Gajovic S, Porro F, Luzzatto L, Baralle FE. Mild spherocytic hereditary elliptocytosis and altered levels of $\alpha$ - and $\gamma$-adducins in $\beta$-adducindeficient mice. Blood 2000; 95: 3978-3985.

2 Porro F, Costessi L, Marro M, Baralle F, Muro A. The erythrocyte skeletons of beta-adducin deficient mice have altered levels of tropomyosin, tropomodulin and EcapZ. FEBS Lett 2004; 576: 36-40.

3 Castejon AM, Alfieri AB, Hoffmann IS, Rathinavelu A, Cubeddu LX. Alpha-adducin polymorphism, salt sensitivity, nitric oxide excretion, and cardiovascular risk factors in normotensive Hispanics. Am J Hypertens 2003; 16: 1018-1024.

4 Tikhonoff V, Kuznetsova T, Stolarz K, Bianchi G, Casiglia E, Kawecka-Jaszcz K et al. B-adducin polymorphisms, blood pressure, and sodium excretion in three European population. Am J Hypertens 2003; 20: 840-846.

5 Wang JG, Barlassina C, Bianchi G, Fagard R, Zagato L, Staessen JA. Haematological phenotypes in relation to the C1797T $\beta$-adducin polymorphism in a Caucasian population. Clin Sci 2003; 104: 369-376.

6 Lew V, Tiffert T, Etzion Z, Perdomo D, Daw N, MacDonald L et al. Distribution of dehydration rates generated by maximal Gardos-channel activation in normal and sickle red blood cells. Blood 2005; 105: 361-367.

7 Staessen AJ, Roels H, Emelianov D, Vangronsveld J, Kuznetsova T, Thijs L et al. Environmental exposure to cadmium, forearm bone density, and risk of fractures: prospective population study. Lancet 1999; 353: 1140-1144.

8 Staessen AJ, Fagard R, Amery A. Life style as a determinant of blood pressure in the general population. Am J Hypertens 1994; 7: 685-694.

9 Livak KJ, Flood SJ, Marmaro J, Giusti W, Deetz K. Oligonucleotides with fluorescent dyes at opposite ends provide a quenched probe system useful for detecting PCR product and nucleic acid hybridization. PCR Methods Appl 1995; 4: 357-362.

10 Brand E, Wang JG, Herrmann SM, Staessen JA. An epidemiological study of blood pressure and metabolic phenotypes in relation to the $\mathrm{G} \beta_{3}$ C825T polymorphism. J Hypertens 2003; 21: 729-737.

11 Tripodi G, Casari G, Tisminetzky S, Bianchi G, Devescovi G, Muro A et al. Characterisation and chromosomal localisation of the rat $\alpha$ - and $\beta$-adducinencoding genes. Gene 1995; 166: 307-311.

12 Glorioso N, Filigheddu F, Troffa C, Soro A, Parpaglia $\mathrm{PP}$, Tsikoudakis A et al. Interaction of the $\alpha 1-\mathrm{Na}$, $\mathrm{K}$-ATPase and $\mathrm{Na}, \mathrm{K}, 2 \mathrm{Cl}$-cotransporter genes in human essential hypertension. Hypertension 2001; 38: 204-209.

13 Castejon AM, Alfieri AB, Hoffmann IS, Rathinavelu A, Cubeddu LX. Alpha-adducin polymorphism, salt sensitivity, nitric oxide excretion, and cardiovascular risk factors in normotensive Hispanics. Am J Hypertens 2003; 16: 1018-1024.

14 Barlassina C, Norton GR, Samani NJ, Woodwiss AJ, Candy GC, Radevski I et al. Adducin polymorphism in hypertensives of South African ancestry. Am J Hypertens 2000; 13: 719-723.

15 Glorioso N, Filligheddu F, Cusi D, Troffa C, Conti M, Natalizio $\mathrm{M}$ et al. adducin 460Trp allele is associated with erythrocyte $\mathrm{Na}$ transport in North Sardinian primary hypertensives. Hypertension 2002; 39(part 2): 357-362.

16 Gardos G. The function of calcium in the potassium permeability of human erythrocytes. Biochim Biophys Acta 1958; 30: 653-654.

17 Lew V, Ferreira H. Calcium Transport and the Properties of a Calcium-Activated Potassium Channel in Red Cell Membranes 1978. Academic Press: London, UK.

18 Resnick LM, Gupta RK, Laragh JH. Intracellular free magnesium in eythrocytes of essential hypertension: Relation to blood pressure and serum divalent cations. Proc Natl Acad Sci USA 1984; 81: 6511-6515.

19 Simons TJ. Calcium-dependent potassium exchange in human red cell ghosts. J Physiol 1976; 256: 227-244. 